\title{
Asymptomatic submandibular giant calculus left for 24 years: A case report
}

\author{
Karnoon Shamsoon ${ }^{1,2}$, Fumiya Harada ${ }^{3}$, Shintaro Yodogawa ${ }^{1}$, Shigehiro Takeda ${ }^{1}$, Saki Fujii ${ }^{1}$, Yoshihiro Abiko ${ }^{4}$, Eiji Nakayama ${ }^{5}$, Takashi \\ Saito $^{2}$, Hiroki Nagayasu ${ }^{3}$ and Tsuyoshi Shimo ${ }^{1 *}$ \\ ${ }^{1}$ Division of Reconstructive Surgery for Oral and Maxillofacial Region, Department of Human Biology and Pathophysiology, School of Dentistry, Health Sciences \\ University of Hokkaido, Tobetsu, Japan \\ ${ }^{2}$ Division of Clinical Cariology and Endodontology, Department of Oral Rehabilitation, School of Dentistry, Health Sciences University of Hokkaido, Tobetsu, \\ Japan \\ ${ }^{3}$ Division of Oral and Maxillofacial Surgery, Department of Human Biology and Pathophysiology, School of Dentistry, Health Sciences University of Hokkaido, \\ Tobetsu, Japan \\ ${ }^{4}$ Division of Oral Medicine and Pathology, Department of Human Biology and Pathophysiology, School of Dentistry, Health Sciences University of Hokkaido, \\ Tobetsu, Japan \\ ${ }^{5}$ Division of Oral and Maxillofacial Radiology, Department of Human Biology and Pathophysiology, School of Dentistry, Health Sciences University of Hokkaido, \\ Tobetsu, Japan
}

\begin{abstract}
Sialolithiasis develops from salivary gland calculi and leads to salivary gland obstruction and recurrent painful swelling of the involved gland. A 54-year-old Japanese man had experienced right submandibular swelling since 1995, but he left it untouched because there were no severe symptoms. Eventually, he noticed an increase in swelling and pain, and thus he was referred to our clinic in October 2018. Computed tomography revealed hard tissue of about $30 \times 20 \mathrm{~mm}$ located in the gland body. The patient underwent surgical extraction of the submandibular salivary gland under general anesthesia in December 2018. Energy dispersive $\mathrm{x}-$ ray fluorescence analysis revealed that the main components of the sialolithiasis were $\mathrm{Ca}: 78.6 \%$ and $\mathrm{P}: 21 \%$. Histological analysis showed atrophy and fibrosis of the submandibular salivary gland. In this report, we present this case of an asymptomatic submandibular giant calculus left untreated for 24 years.
\end{abstract}

\section{Introduction}

Sialolithiasis is calculus formation that occurs due to mineralization within the duct lumen of debris such as bacterial colonies, epithelial cells, and/or mucus buffers. It often occurs in the submandibular gland, and it is more common in middle age [1]. Typical symptoms are colic pain and swelling in the lower jaw when eating, and the size of the calculus is usually several $\mathrm{mm}$. The pathological condition is characterized by the obstruction of a salivary gland or its excretory duct due to the formation of calculi, resulting in salivary ectasia and even determining the subsequent dilatation of the salivary gland [2]. Pain and swelling occur in occasional cases, and may be localized or diffuse. When present, symptoms are more severe in cases in which the duct is blocked for a long time, and they may be intensified during meals [3]. Pain may gradually decrease with salivary flow and may also be related to infection [4]. The occurrence of fever and local reactive lymphadenopathy is thus highly likely [5]. However, less frequently, the patient may be asymptomatic, regardless of the size of the calculus [1] Calculi tend to develop in the submandibular gland and can vary in size from less than one millimeter to a few centimeters at their largest diameter, but they are typically less than $10 \mathrm{~mm}$ in diameter. Giant calculi are defined a those exceeding $15 \mathrm{~mm}$ in any one dimension [6]. Here we report the case of a 54-year-old Japanese male with asymptomatic giant right submandibular calculi left untreated for 24 years.

\section{Case presentation}

A 54-year-old Japanese male was referred to our clinic with a chief complaint of swelling and pain in the right submandibular region. He had experienced the swelling in 1995 but he left it untouched because there were no severe symptoms. He noticed an increase in the swelling and pain, and thus he was referred to our clinic in October 2018. According to his history, the patient was under treatment for hypertension. His blood pressure was $120 / 96 \mathrm{mmHg}$, and he was diagnosed with old myocardial infarction and atrioventricular block leading to bradycardia on the basis of an electrical cardiograph; however, neither of these conditions has pathological significance. A clinical examination found obvious swelling in his right submandibular area (Figure 1). The mass-like swelling was palpable and was the size of walnut. The mass had an elastic soft texture, mobility, and was painful when touched. Intraorally, the right mouth floor mucosa was

${ }^{\star}$ Correspondence to: Tsuyoshi Shimo, Division of Reconstructive Surgery for Oral and Maxillofacial Region, Department of Human Biology and Pathophysiology, School of Dentistry, Health Sciences University of Hokkaido, 1757 Ishikari-Tobetsu, Hokkaido 061-0293, Japan, E-mail: shimotsu@hoku-iryo-u.ac.jp

Key words: sialolithiasis, submandibular gland

Received: February 21, 2020; Accepted: February 26, 2020; Published: February 28,2020 
reddened, mildly swollen, and tender. Yellow-white viscous liquid spilled out from the sublingual salivary papilla. A panoramic X-ray examination revealed a curved, elliptical radiopaque mass in the right submandibular salivary gland region (Figure 2A). Evaluation of the bone window on Computed tomography (CT) revealed a hard tissue about $30 \times 20 \mathrm{~mm}$ in size located in the gland body (Figure 2B). No neurological disturbance of the facial, lingual, or sublingual nerve was evident. Based on the examinations, a clinical diagnosis of right submandibular sialolithiasis resulting in submandibular sialadenitis was made. To reduce inflammation, amoxicillin $750 \mathrm{mg} /$ day was orally administered for 4 days. In December 2018, the patient underwent surgical extraction of the submandibular salivary gland under general anesthesia after the inflammation was reduced. Figure 3 shows the facets of the submandibular gland and the internal calculi. The calculi were flexed in line with the mylohyoid muscle, and the surface was rough and grayish-yellow in color. Figure 4 shows the hematoxylin-eosin staining of the extracted submandibular gland, and the main composition of the region was inflammatory saliva tissue. Mild-to-severe migration of lymphocytes and plasmacytes, which are chronic inflammatory cells, was observed around the salivary tissue. Some salivary tissue degenerated into adipo-tissue. Acinic cells had atrophied, and the saliva duct was extended as a result of migration of the inflammatory cells. The pathological diagnosis was chronic sialadentitis and sialolithiasis. The calculi were analyzed using energy dispersive $\mathrm{x}$-ray fluorescence (EDX7000, Shimadzu, Tokyo, Japan) (Figures 1-3). The main components of the sialolithiasis were Ca: $78.6 \%, \mathrm{P}: 21 \%$, S: $0.25 \%$, Fe: $0.07 \%$, and $\mathrm{Cu}$ : $0.04 \%$ (Figure 5 ). The patient has remained in good condition since the surgery.

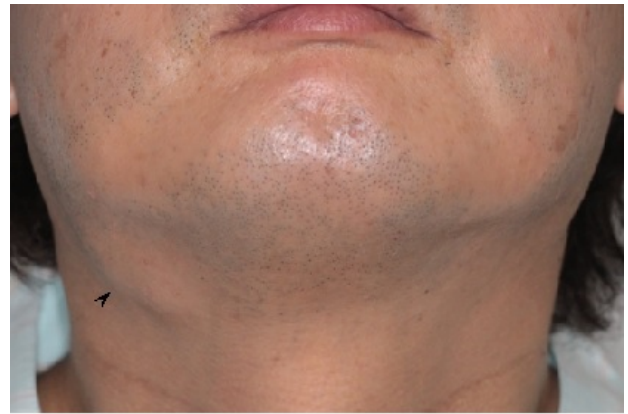

Figure 1. Clinical picture of the patient. Arrow head, right submandibular gland swelling

A

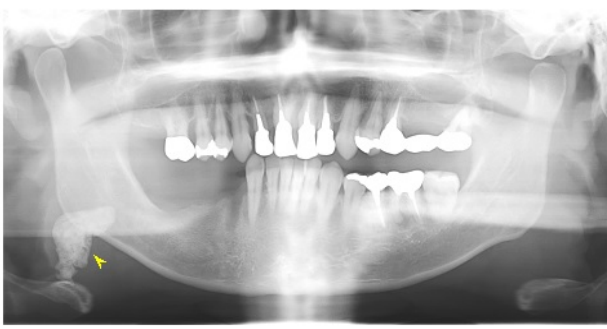

B

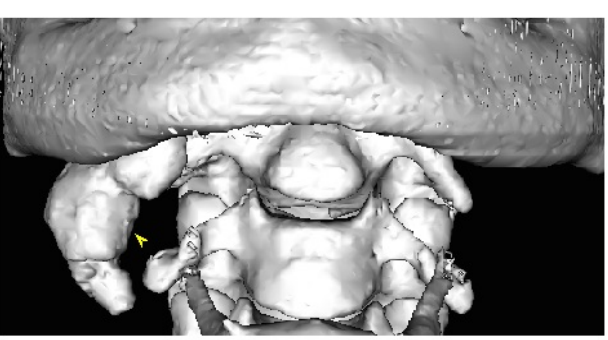

Figure 2. Panoramic X-ray (A), 3-D CT image (B)

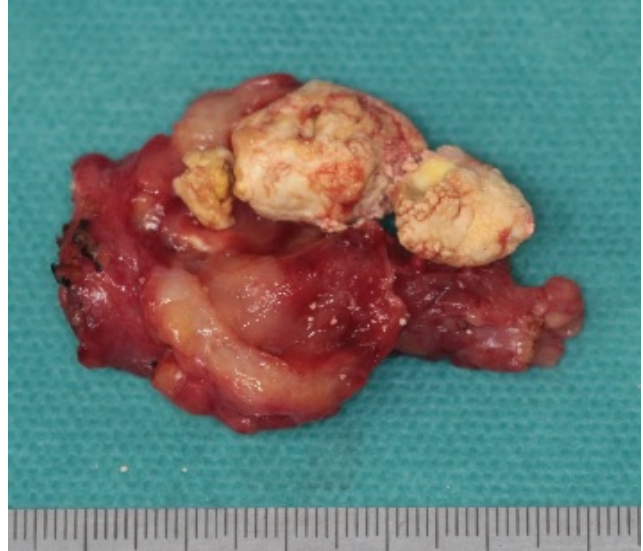

Figure 3. Photo of the calculus in divided submandibular gland

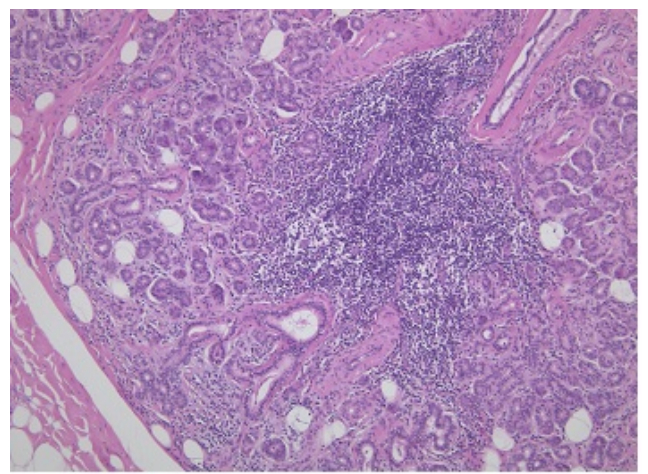

Figure 4. Histology of the submandibular gland. The acinic cells atrophied and the saliva duct was extended as a result of the migration of inflammatory cells $(\times 100)$

\section{Discussion}

Most salivary calculi are about $10 \mathrm{~mm}$ in diameter, and those 10 $\mathrm{mm}$ in diameter or smaller account for about 70 to $90 \%$ of the total, but this case was estimated to have increased to $30 \times 20 \mathrm{~mm}$ over a long period of time [7]. Although most giant glandular calculi are associated with pain, particularly when located within ducts [8], this patient was completely asymptomatic. This absence of symptoms may have been related to the incomplete obstruction of the duct, which enabled the secretion of some amount of saliva and thus allowed the calculus to develop without symptoms, as has been suggested in other cases [9]. Due to the absence of symptoms, the patient did not seek dental care, allowing the calculus to increase in size over a long period of time. It is important to point out that even in asymptomatic cases; giant calculi should be removed as soon as possible to avoid the potential for complications such as atrophy of the gland, parenchymal fibrosis, sialadenitis, or even extra-oral fistula [10]. In this case, the extracted submandibular gland was contained inflammatory and degenerated saliva tissue. Although the exact etiology is unknown, calculi are thought to occur as a result of the deposition of mineral salts around an initial nidus consisting of salivary mucin, bacteria, or desquamated epithelial cells [11]. Salivary stagnation, increased alkalinity and calcium content of the saliva, inflammation or infection of the salivary duct or gland, and physical trauma to the salivary duct or gland may predispose an individual to calculus formation [12]. Calculi are believed to be more common in the submandibular duct system for the following reasons: (1) the submandibular excretory duct is wider in diameter and longer; (2) the salivary flow in the submandibular gland goes against gravity; (3) the submandibular salivary secretion is more alkaline than the parotid saliva; (4) the submandibular saliva contains a greater quantity 

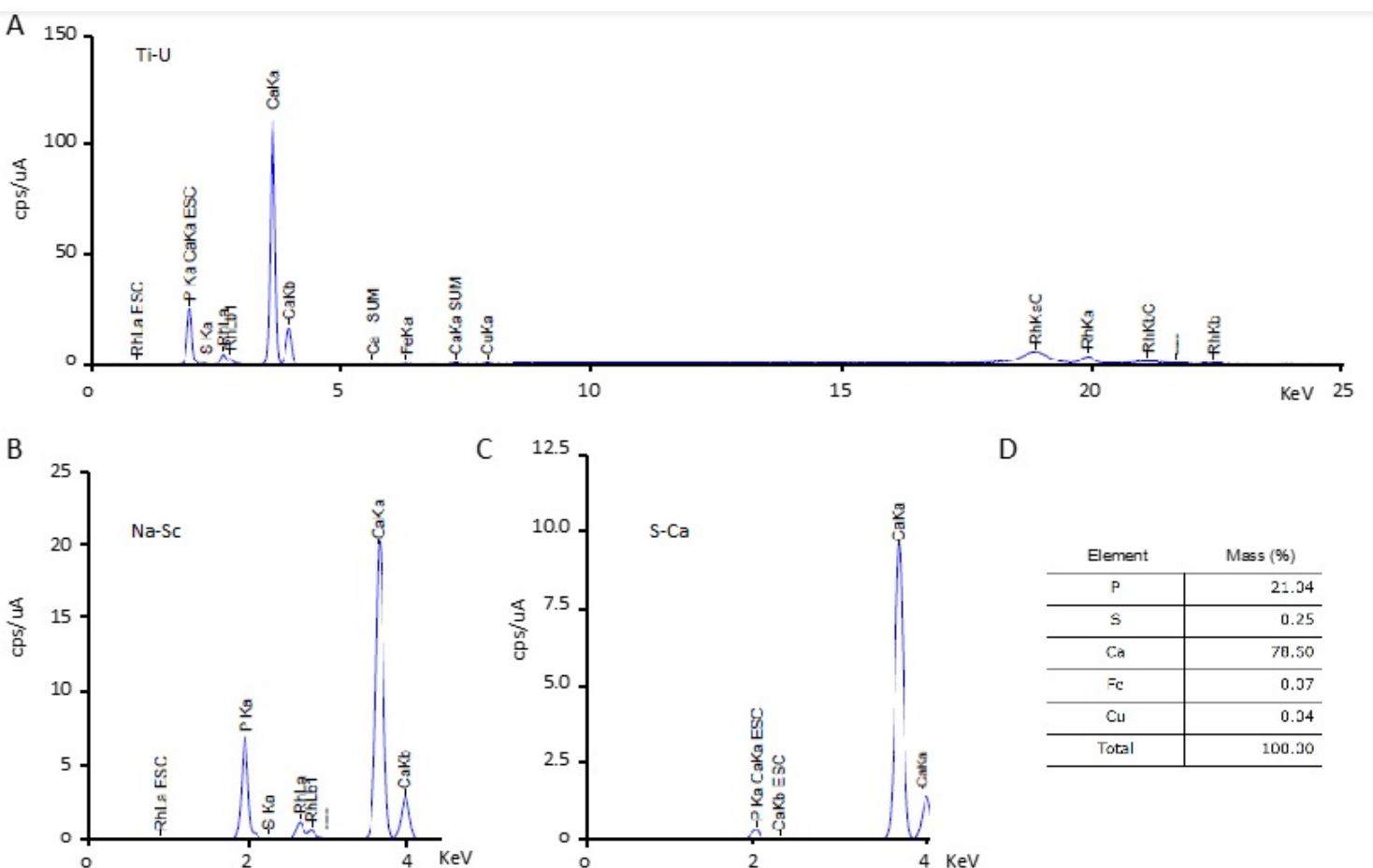

D

Figure 5. Energy dispersive x-ray fluorescence spectrum and the components of the calculus. A-C: Spectrum (cps/uA) of the energy dispersive x-ray fluorescence. D: Components of the calculus

of mucin proteins [13]. As in this case, the calculus might increase in size, becoming a giant calculus, and remain asymptomatic for a long period if the calculus is located in a duct that is able to dilate, thus allowing normal secretion of the salivary flow around the calculus [8].

In general, the components of salivary calculi are mainly inorganic substances, with small amounts of organic substances. About $80 \%$ of the components are inorganic substances, including about $70 \%$ calcium phosphate and about $10 \%$ calcium carbonate, magnesium phosphate, iron oxide, etc [14]. The constituents of the submandibular salivary calculus are $\mathrm{Ca}$ and $\mathrm{P}$ as the main components, and also $\mathrm{Mg}, \mathrm{Na}, \mathrm{Cl}$, $\mathrm{Si}, \mathrm{Fe}$ and $\mathrm{K}$ [15]. The constituents of the parotid salivary calculus also include $\mathrm{Ca}, \mathrm{P}, \mathrm{Mg}, \mathrm{S}, \mathrm{Cl}$, and $\mathrm{K}$. [16]. The constituent elements of the salivary calculus in this case were mainly $\mathrm{Ca}(78.6 \%)$ and $\mathrm{P}(21.4 \%)$, and $\mathrm{S}, \mathrm{Fe}$, and $\mathrm{Cu}$ were also observed. On the other hand, $\mathrm{Ca}, \mathrm{P}, \mathrm{S}, \mathrm{Mg}$, $\mathrm{Na}, \mathrm{K}$, and $\mathrm{Cl}$ have been detected as constituents of a small salivary gland calculus[17]. Calcium oxalate and phosphocalcium were found in a component analysis of a kidney calculus [18]. These findings suggest that $\mathrm{Ca}$ and $\mathrm{P}$ are common as the main components of salivary calculi and other calculi in the body.

The symptoms begin whenever the lumen of the Wharton duct is obstructed by a salivary calculus, with the resultant accumulation of saliva causing pain and swelling of the involved gland. Although our patient had been asymptomatic for 24 years, salivary stasis may have resulted in a rise of bacteria into the glandular parenchyma, and thus may eventually have caused recurrent infections. Long-term obstruction of the saliva flow and recurrent infections may have resulted in salivary tissue degenerating into adipo-tissue and ultimately fibrosis [19].

Most submandibular calculi are detected as radiopaque formations in plain radiographs and as radiolucent filling defects in sialography. Approximately $20 \%$ of calculi are not radiopaque, and sialography or sialendoscopy may be required to diagnose them. Salivary calculi are usually unilateral and do not cause dry mouth [20]. Bodner evaluated various imaging modalities for the diagnosis of giant calculi and found that panoramic radiograph and axial CT were comparable in their precise preoperative estimation of calculus size [6]. CT is very accurate at detecting and defining the location of salivary calculi. Sialography is rarely indicated and should be restricted to cases of sialadenitis related to radiolucent calculi [21]. CT scans have become the preferred modality for detecting gland salivary calculus, because they are not invasive like sialography [2]. The 3D-CT image analysis in this case showed that the salivary calculus was bent at a right angle by the mylohyoid muscle and had a shape that matched the shape of the submandibular gland.

The ultimate objective of giant calculus treatment is to restore a normal salivary flow. Whenever the calculus can be palpated intraorally, the best option is to remove it through an intraoral approach [22]. Sialadenoscopy, which is a non-invasive technique, can be used to manage large calculi as well as ductal obliteration. The $\mathrm{CO}_{2}$ laser, because of its advantages of minimal bleeding, less scarring, clear vision, and minimal post-operative complications, is gaining its popularity in the treatment of sialolithiasis [21]. However, removal of the submandibular gland is indicated for submandibular gland calculi with recurrent infections, as in this case.

\section{Competing interests}

None

\section{Funding}

None.

\section{Ethical approval}

None required.

\section{Consent}

Informed consent was taken. 


\section{Authors' contributions}

All authors have contributed equally in the treatment, data collection, data analysis or interpretation and writing this paper.

\section{Conflict of interest}

None of the authors have any conflict of interest.

\section{References}

1. Lustmann J, Regev E, Melamed Y (1990) Sialolithiasis. A survey on 245 patients and a review of the literature. Int J Oral Maxillofac Surg 19: 135-138. [Crossref]

2. Oteri G, Procopio RM, Cicciù M (2011) Giant Salivary Gland Calculi (GSGC): Report of two cases. Open Dent J 5: 90-95. [Crossref]

3. Cherian NW, Vichattu SV, Thomas N, Varghese A (2014) Wharton's duct sialolith of unusual size: A case report with. a review of the literature. Case Rep Dentistry 2014: $1-7$.

4. Delli K, Spijkervet FK, Vissink A (2014) Salivary gland diseases: infections, sialolithiasis and mucoceles. Monogr Oral Sci 24: 135-148.

5. Leite TC, Blei V, de Oliveira DP, Robaina TF (2011) Giant Asymptomatic Sialolithiasis. Int J Oral-Med Sci 103: 175-178.

6. Bodner L (2002) Giant salivary gland calculi: Diagnostic imaging and surgical management. Oral Surg Oral Med Oral Pathol Oral Radiol Endodontol 94: 320-323.

7. Thomas BL, Brown JE, McGurk M (2010) Salivary gland disease, salivary glands. development, adaptations and disease. Front Oral Biol 14: 129-146.

8. Rai M, Burman R (2009) Giant submandibular sialolith of remarkable size in the comma area of Wharton's Duct: a case report. J Oral Maxillofac Surg 67: 1329-1332. [Crossref]

9. Becker M, Marchal F, Becker CD, Dulguerov P (2000) Sialolithiasis and salivary ductal stenosis: diagnostic accuracy of MR sialography with a three-dimensional extendedphase conjugate-symmetry rapid spin-echo Sequence. Radiology 217.
10. Nupur B, Sanjib M, Surajit K (2015) Giant Parotid Sialolithiasis: Report of a case with review of literature. Int J Scient Res Manag 3: 2595-2604.

11. Austin T, Davis J, Chan T (2004) Sialolithiasis of submandibular gland. J Emerg Med 26: 221-223.

12. Sunder VS, Chakravarthy C, Mikkilinine R, Mahoorkar S (2014) Multiple bilateral submandibular gland sialolithiasis. Nig J Clin Pract 17.

13. Pramanik R, Osailan SM, Challacombe SJ, Urquhart D, Proctor GB (2010) Protein and mucin retention on oral mucosal surfaces in dry mouth patients. Eur J Oral Sci 118: 245-253.

14. Kraaij S, Brand HS, Meij EH, Visscher V (2018) Biochemical composition of salivary stones in relation to stone- and patient-related factors. Med Oral Patol Oral Cir Bucal 23: e540-544. [Crossref]

15. Kasaboglu O, Er N, Tumer C, Akkocaoglu M (2004) Micromorphology of sialoliths in submandibular salivary gland: a scanning electron microscope and X-Ray diffraction analysis. J Oral Maxillofac Surg 62: 1253-1258.

16. Taniguchi N, Mori K, Fukunaga S, Takeshima H, Iida S, et al. Two cases of parotid gland sialolithiasis: analysis of its components. J Meikai Dent Med 35: 125-135.

17. Yamazaki Y, Sakamoto E, Takeshima H, Tatsuta T, Yamamoto Y (1989) A case of sialolithiasis occuring via supralabial minor salivary glands. Japanese J Oral Maxillofac Surg 35: 2596-2605.

18. Khan SR, Pearle MS, Robertson WG, Gambaro G, Canales BK, et al. (2016) Kidney stones. Nature Rev Dis Primers 2: 16008.

19. Arslan S, Vuralkan E, Çobanog `lu B, Arslan A, Ural A (2015) Giant sialolith of submandibular gland: report of a case. J Surg Case Rep 2015.

20. Iqbal A, Gupta AK, Natu SS, Gupta AK (2012) Unusually large sialolith of Wharton's duct. Ann Maxillofac Surg 2: 70-73. [Crossref]

21. Patil S, Sharma S, Prasad LK (2009) Sumandibular megalith with erosion of floor of mouth. A rare case report. World Articles in Ear, Nose and Throat 2: 1-2.

22. McGurk M, Escudier MP, Brown JE (2005) Modern management of salivary calculi Br J Surg 92: 107-112.

Copyright: (2020 Shamsoon K. This is an open-access article distributed under the terms of the Creative Commons Attribution License, which permits unrestricted use, distribution, and reproduction in any medium, provided the original author and source are credited. 